\title{
A POLÍTICA DE CONCESSÃO DE BENEFÍCIOS FISCAIS NO ESTADO DO TOCANTINS: O QUE PENSAM OS ATORES INSTITUCIONAIS?
}

\author{
THE POLICY GRANTING OF TAX BENEFITS IN THE STATE \\ OF TOCANTINS: WHAT THEY THINK THE INSTITUTIONAL \\ ACTORS?
}

Waldecy Rodrigues

Universidade Federal do Tocantins - Palmas - TO - Brasil

Maria Rosicleide do Nascimento Araújo

Secretaria da Fazenda do Estado do Tocantins - Palmas - TO - Brasil

\begin{abstract}
Resumo: O objetivo deste trabalho foi analisar a percepção e avaliação dos atores institucionais sobre a política de concessão de benefícios fiscais no Estado do Tocantins. Metodologicamente, foram realizadas entrevistas junto aos empresários beneficiados, agentes representativos do setor empresarial e do governo e membros do Conselho de Desenvolvimento Econômico do Estado. Os dados qualitativos foram posteriormente trabalhados pela análise de conteúdo. Os principais resultados obtidos ressaltaram a grande relevância da política de incentivos fiscais na atração de empresas para o Estado, porém com um baixo nível de institucionalização e confiabilidade. Esses aspectos ampliam os níveis de incerteza, e mesmo o Estado tendo políticas consideradas como atrativas para o investidor, seus custos de transação atuam como inibidores dos seus efeitos.

Palavras-chave: Neoinstitucionalismo Econômico. Arranjo Institucional. Política de benefícios fiscais no Tocantins.
\end{abstract}

\begin{abstract}
The objective of this research was to analyze the perception and evaluation of institutional actors about the policy of granting tax benefits in the State of Tocantins. Methodologically, interviews were conducted with entrepreneurs benefited, agents representing the business sector and the Government and members of the Board of economic development of the State. The qualitative data were subsequently worked out by content analysis. The main results obtained stressed the great relevance of the tax incentive policy on attracting companies to the State, but with a low level of institutionalization and reliability. These features extend the levels of uncertainty, and even the State having policies considered attractive to the investor, your transaction costs act as inhibitors of its effects.
\end{abstract}

Keywords: Economic neo-institutionalism. Institutional arrangement. Tax benefits policy in Tocantins.

\section{INTRODUÇÃO}

O Estado do Tocantins, o mais recente da federação brasileira, criado na Constituição de 1988, busca, estrategicamente, romper com seu histórico de subdesenvolvimento, principalmente relacionado com sua baixa industrialização e restrito mercado interno. Para esse fim, tem adotado políticas consideradas como "agressivas" na atração de investimentos produtivos. Uma dessas políticas é a tributária, onde o Estado oferece benefícios fiscais sobre o Imposto sobre circulação de Mercadorias e Serviços - ICMS às empresas que queiram se instalar 
ou expandir seus negócios em seu território, objetivando, com isto, a geração de emprego e renda, e investimentos locais (SIC-TO, 2013).

Atualmente, o Estado do Tocantins possui 12 tipos de programas de benefícios fiscais, que beneficiaram 943 empresas entre 1999 e 2012. Desse total, $80 \%$ de todos os incentivos fiscais concedidos foram direcionados para o setor industrial e de comércio atacadista. Entretanto, destaca-se que apenas 52\% desses incentivos estão ativos atualmente.

Alguns questionamentos naturalmente surgem diante da política de concessão de benefícios fiscais, uma vez que eles representam, em última instância, uma menor arrecadação tributária futura e, por sua via, uma menor disponibilidade orçamentária para a prestação de serviços públicos. A usual contra argumentação é que, se não fosse a existência dos incentivos fiscais, as localidades consideradas como periféricas teriam seu nível de atração econômica para os investimentos drasticamente reduzido e, por consequência, uma arrecadação tributária ainda menor.

Um ponto que vem merecendo destaque na análise de políticas de atração de investimento, em especial para regiões periféricas, é compreender não apenas como as políticas são estabelecidas em suas regras formais, mas, sobretudo, como são alicerçadas em seus ditos mecanismos informais de governança. Em outras palavras, adianta pouco ter uma ousada política de benefício fiscal se os contratos não têm um ambiente favorável em mecanismos de governança e até mesmo o próprio ambiente político.

North (1998), um dos principais expoentes do Neoinstitucionalismo Econômico - NE, já chamava atenção que o ambiente institucional é estruturado pelas chamadas regras formais - as escritas, como constituições, leis, regulamentos e direitos de propriedade, ou informais - as não escritas, como costumes, condutas, códigos, valores e tradições. Ayala Espino (2003) também destaca a importância de se ter arranjos institucionais eficazes para fomentar a atração de investimentos e o crescimento econômico. Porém, a maior ou menor eficácia dos novos arranjos institucionais depende não só de suas regras explícitas, mas, em especial, de aspectos específicos que envolvem essas situações contratuais, como a agilidade e transparência. O autor destaca a eficiência ou não dessas instituições no que se refere à viabilidade da geração de um sistema de incentivos ou desincentivos econômicos e extra econômicos. Isso ocorre porque as instituições (formal e informal) definem o marco de restrições legais e extralegais (econômico, social, cultural, etc.) por meio do qual os indivíduos agem, organizam-se e intercambiam.

Pergunta-se, centralmente, nesta pesquisa, como os atores institucionais, em especial os empresários beneficiados, avaliam a política de concessão de benefícios fiscais do Estado do Tocantins, não só as regras estabelecidas, como também o cumprimento das mesmas e seus aspectos informais de governança?

Assim, este artigo tem por objetivo realizar uma análise institucional da política estadual tocantinense de concessão de benefícios fiscais, entre 1999 e 2012, identificando e avaliando as perspectivas que os atores, em especial os empresários, têm dessa política, considerando seus mecanismos formais e informais de governança. 


\section{ARRANJOS INSTITUCIONAIS E DESEMPENHO ECONÔMICO}

Com o retorno das discussões sobre o desenvolvimento econômico, nas últimas décadas, muito se tem debatido sobre o papel que as instituições podem exercer para um melhor desempenho econômico, visto que a teoria econômica tradicional não tem conseguido dar respostas satisfatórias aos problemas da desigualdade no desempenho econômico entre as nações. Essas diferenças ou desigualdades, segundo Ayala Espino (1999), podem ser explicadas pela teoria das instituições, podendo esta ser um guia na definição de qual tipo de instituições são requeridas atualmente.

Destacam-se como pilares da economia neoinstitucional, Ronald Coase, Douglas North e Oliver Williamson, ganhadores do Prêmio Nobel em economia nos anos de 1991, 1993 e 2009, respectivamente. A partir dos trabalhos seminais desses autores, vem-se ampliando, ao longo das últimas décadas, estudos tratando da qualidade das instituições para o desenvolvimento econômico e o papel do Estado nesta relação.

Coase é considerado o pioneiro nos estudos dos custos de transação, e atribui à redução dos custos de transação o surgimento e a escolha de uma forma particular de organização, sendo este um dos pressupostos básicos do NE (1993). Para esse autor, os recursos neoclássicos de mercado eficiente, só são obtidos quando há custos de transação e, quando estes são significativos, as instituições passam a ter importância. Nesse caso, "um conjunto de instituições políticas e econômicas que ofereça transações de baixo custo viabiliza a existência de mercados de produtos e fatores eficientes necessários ao crescimento econômico" (NORTH, 1998, p. 8).

O modelo conceitual de análise institucional de Williamson, de acordo com Ayala Espino (1999), analisa, em particular, a firma como sendo uma forma de organização econômica importante, que retrata claramente os problemas ligados aos custos de transação. Nesse caso, as formas de organizações ou estruturas de "governance" (firma, mercado, organização ou redes) resultam da procura dos agentes econômicos em minimizar os custos de transação. Contudo, não se pode garantir que essas formas de alocação de recursos (mercado e organizações), por si só, promovam a eficiência desejada (WILLIAMSON, 2000). A "ênfase nos aspectos internos da firma, as noções de 'mercados' e 'hierarquias', juntamente com a presença de 'falhas de mercado'", constituem o campo de análise do neoinstitucionalismo econômico para Williamson" (CONCEIÇÃO, 2001, p. 112).

O pressuposto de que as instituições são as regras do jogo em uma sociedade ou, mais especificamente, são as restrições estabelecidas pelo homem (criação humana) para organizar e disciplinar as interações humanas, podendo ser formais ou informais, é atribuído a North $(1998,2001)$.

As instituições formais, segundo Ayala Espino (1999), são regras escritas em constituições, leis, regulamentos, entre outras, criadas pelos indivíduos para resolver problemas específicos de coordenação econômica, social e política, cuja aplicação e cumprimento se dão compulsoriamente, requerendo, assim, de um poder coercitivo para fazê-las cumprir, estando estas vinculadas ao domínio público.

As informais, por sua vez, são as regras não escritas, as que se acumulam ao longo do tempo, e que são registradas nos usos e costumes, sendo, portanto, fruto 
da evolução dos códigos de conduta, dos valores, das ideias e tradições das sociedades. Essas regras são autocumpridas ou autorrealizáveis, ou seja, não requerem nenhuma força externa (poder público) que obriguem seu cumprimento, e suas sanções são morais e privadas (AYALA ESPINO, 1999).

North (1998) afirma que são as políticas que determinam as regras formais e os direitos de propriedade em uma economia. Nesse caso, uma condicionante importante para que o problema de se conseguir um bom desempenho econômico seja resolvido, é que se tenham estruturas institucionais que proporcionem estímulos positivos à geração dos mais variados caminhos para que se alcance tal solução. As organizações descritas por North (1998) são consideradas como aquelas geradas pelo conjunto de oportunidades determinadas pelo arcabouço institucional, e seu curso evolutivo obedece à estrutura de incentivos inclusos nesse arcabouço. Assim, elas são formadas por grupos de indivíduos dedicados a alguma atividade executada com determinado fim, ou seja, são frutos das limitações institucionais. Então, se as instituições são as "regras do jogo", as organizações são os "jogadores".

Conforme afirma North (2001), a principal função das instituições em uma sociedade é minimizar as incertezas, estabelecendo um arranjo estável à interação humana, isto não quer dizer que esse arranjo seja necessariamente eficiente.

Ayala Espino (1999) diz que assim como as organizações requerem de certas regras e normas para operar em um ambiente de cooperação, o Estado também precisa de certos mecanismos legais para regular as suas ações sobre as estruturas do sistema econômico. A complexidade no mercado exige leis que o coordene, e o Estado é a via para fixar e fazer cumprir as regras coordenadoras desse mercado.

Chama-se a atenção para o fato de que, segundo Ayala Espino (1999), as nações produzem dentro de suas fronteiras não aquilo que a sua dotação orçamentária permitem, mas o que permite as políticas e as instituições. Nesse ponto, faz sentido a exigência de se ter boas instituições para que se resulte em desenvolvimento.

Constata-se que o NE atribui às instituições um papel crucial para a dinâmica econômica e o desenvolvimento de qualquer sistema econômico. Nesse sentido, Ayala Espino (1999) esclarece que essas instituições podem ser eficientes ou não, no sentido de gerar um sistema de incentivos ou desincentivos econômicos e extraeconômicos, para que os indivíduos se envolvam em processos de intercâmbios socioeconômicos complexos, como o investimento, a poupança, a inovação tecnológica, a ação coletiva, projetos, e a implementação e administração de políticas públicas. Segundo o autor, isso ocorre porque as instituições (formal e informal) definem o marco de restrições legais e extralegais (econômico, social, cultural, etc.) por meio do qual os indivíduos agem, se organizam e negociam.

De acordo com Ayala Espino (1999), há razão quando se afirma que a eficiência e o bem estar são processos cuja solução não depende exclusivamente das instituições, ou do mercado, ou das políticas públicas, mas de um complexo arranjo institucional que é simultaneamente econômico, social, político e institucional. $\mathrm{O}$ autor afirma que um arranjo institucional que se mostra eficiente em uma economia não, necessariamente, será em outra, sendo necessário que se adaptem criativamente às condições estruturais especificas da cada economia. 
No Brasil, a maioria dos estados lança mão de um arranjo institucional, em sua grande maioria, baseado em políticas públicas de incentivo fiscal para fomentar o desenvolvimento de suas regiões. Um dos objetivos dos governos ao criarem políticas de incentivos ao desenvolvimento regional é poder atrair empresas e investimentos para as regiões menos desenvolvidas, e, para a efetividade da mesma, é necessário reconhecer a natureza institucional das empresas, haja vista que esses incentivos influenciam na decisão sobre produzir e vender em um mercado em específico. De acordo com Pedroza Júnior (2011), essa tomada de decisão é tida como inconstante e vulnerável às várias alterações que acontecem no meio empresarial, logo, promover o desenvolvimento regional fundamentado num instrumento como este, com certeza, não produz resultados de longo prazo.

Sob o ponto de vista de Pedroza Júnior (et al, 2011), em uma economia de mercado, as organizações são, em especial, as empresas, e, quando estas são criadas como instrumentos de operação de arranjos institucionais, devem estar embasadas em princípios de eficiência adaptativa. Porém, essa necessidade de adaptação, não deve levar a práticas incorretas ou oportunistas, haja vista que regras institucionais constantes são consideradas condição necessária para que uma sociedade se desenvolva.

Para esses autores, os modelos de crescimento endógeno com frequência tem inserido em suas análises o papel que as instituições exercem no crescimento econômico de uma região, isto devido à criação de instituições estáveis. Na opinião deles, o "crescimento econômico no longo prazo só é mantido ou mesmo ampliado quando o arranjo institucional é favorável. [...] Um arranjo institucional desfavorável pode viciar os micromotivos e comprometer toda uma política de concessão de incentivos" (PEDROZA JÚNIOR, p. 829). O argumento principal desSes autores é que os benefícios financeiros por si só não são o melhor caminho para um desenvolvimento sustentado econômico e social, tornando necessário que mudanças acontecessem nas instituições que perpetuam o subdesenvolvimento.

Considera-se aqui o importante papel que as instituições e seus arranjos ou estruturas têm sobre a dinâmica econômica. Entendendo que instituições bem planejadas e eficientes facilitam a coordenação econômica e promovem um melhor desempenho da economia, em contrário, as ineficientes podem colaborar para a perpetuação do atraso econômico.

\section{METODOLOGIA}

Como metodologia de pesquisa, incialmente foi realizada uma revisão bibliográfica da literatura já publicada sobre os temas instituições e $\mathrm{NE}$, buscando, com isto, obter subsídios teóricos e conceituais necessários para a análise da questão proposta. No que se refere à solução do problema, optou-se por uma pesquisa descritiva ${ }^{1}$ de cunho qualitativo, elegendo-se a entrevista como técnica para a obtenção de informações junto aos atores envolvidos na política de concessão dos incentivos fiscais no Tocantins.

1 De acordo com Gil (2009) esse tipo de pesquisa objetiva descrever as características de determinado fenômeno e estabelecer relações entre as variáveis estudadas. 
Assim, no que se refere às entrevistas, estas foram executadas com roteiro semiestruturado, com as informações coletadas, primordialmente, por meio de gravação de áudio, ou seja, de forma oral e individual para cada entrevistado ${ }^{2}$.

O público alvo e tamanho da amostra desta pesquisa foram os atores institucionais envolvidos na política de incentivo fiscal tocantinense, a saber: Grupo 1 - composto por 11 conselheiros (representando o setor público e privado) do Conselho Estadual de Desenvolvimento Econômico (CDE), que deliberam sobre a concessão dos incentivos; Grupo 2 - formado pelos agentes públicos responsáveis pela análise técnica das solicitações dos benefícios, sendo cinco pessoas ao todo (dois do CDE e três da Secretaria da Fazenda do Estado do Tocantins - SEFAZ/TO; e Grupo 3 - formado pelos representantes das empresas beneficiadas com os incentivos fiscais do Estado (Proindústria e Comércio Atacadista). Para os dois primeiros grupos, o convite para participarem da pesquisa foi feito a todos, objetivando alcançar o total desta população, sendo que seis conselheiros e quatro agentes responderam à entrevista.

No Grupo 3, até o momento desta pesquisa, havia um total de 724 benefícios ativos dos mais diversos tipos de incentivos fiscais ofertados pelo Estado do Tocantins (SEFAZ-TO, 2014). Desse total, aproximadamente 383 empresas possuem os benefícios relativos ao objeto deste estudo, qual seja, os beneficiários dos incentivos para a indústria e o comércio atacadista. A princípio, esse era o universo amostral desta pesquisa. Contudo, devido ao tamanho dessa amostra, para esse grupo em especial, o tipo de amostragem foi o não probabilístico ${ }^{3}$, mais especificamente, a intencional. De posse da relação com todos os beneficiados, fornecida pela SEFAZ/TO, escolheu-se então, aleatoriamente, algumas empresas beneficiárias e buscou-se entrar em contato com todas, convidando os seus representantes para participarem da pesquisa e obter o máximo de entrevistas, dentro do tempo necessário para a finalização desta pesquisa.

Diante disso, foi possível a realização de entrevistas com empresários de 44 empresas (32 do ramo da indústria e 12 do comércio atacadista) localizadas nos municípios de Palmas, Paraíso, Porto Nacional, Miracema do Tocantins, Gurupi, Araguaína e Wanderlândia.

Para garantir o anonimato dos entrevistados, estes foram tratados por códigos e números distribuídos aleatoriamente, identificando apenas o grupo e o setor econômico a que pertencem, sendo: " $C$ " para conselheiros do $C D E$, " $A$ " para os agentes públicos, "El" para empresas do setor da indústria, e "EA" para os do comércio atacadista. Assim, obteve-se um código com letras e números para identificar as falas dos mesmos, como por exemplo: EA01 (empresário do setor atacadista 01) e EI01 (empresário do setor da indústria 01).

A forma de análise das entrevistas se deu em duas partes, individuais e complementares entre si. A primeira parte foi feita por meio de tabulação em planilha do Excel dos percentuais relativos aos graus atribuídos nas escalas de preferências e na categorização de importância de algumas opções.

${ }^{2}$ A classificação de entrevista utilizada neste trabalho seguem as determinadas por Colognese e Melo (1999).

3 Amostragem não probabilistica "são amostragens em que há uma escolha deliberada dos elementos da amostra. Não é possivel generalizar os resultados das pesquisas a população, pois as amostras não-probabilísticas não garantem a representatividade da população" (MARTINS e THEÓPHILO, 2009). 
A segunda parte da pesquisa foi realizada via análise de conteúdo das respostas, ou seja, das "falas" dos entrevistados. EsSe procedimento foi realizado utilizando o software WebQDA (Web Qualitative Data Analysis) a partir dos conceitos de Bardin (2009) e Gibbs (2009). Assim, foram identificados os temas, categorias, subcategorias e respectivas questões dos roteiros de cada grupo entrevistado, visando apurar a visão dos atores institucionais sobre a eficácia, em aspectos formais e informais, da política de concessão de benefícios fiscais.

\section{DESCRIÇÃO DOS PROGRAMAS QUE MAIS CONCEDERAM INCENTIVOS FISCAIS NO ESTADO DO TOCANTINS}

Conforme dados levantados, atualmente, o Estado do Tocantins possui 12 dispositivos legais concedendo benefícios fiscais, se observarmos o marco legal disponibilizado no site oficial da SEFAZ-TO (Quadro 01).

Quadro 1. Relação de benefícios fiscais do Tocantins, por tipo e dispositivo legal

\begin{tabular}{|l|l|}
\hline \multicolumn{1}{|c|}{ Tipo de benefício fiscal } & \multicolumn{1}{c|}{ Dispositivo legal em vigor } \\
\hline Produção de carne & Lei $1.173 / 00 ;$ Portaria 1.361/06 \\
\hline Comércio atacadista & Lei $1.201 / 00$ \\
\hline Comércio atacadista de medicamentos & Lei $1.791 / 07$ \\
\hline Complexo agroindustrial & Lei $1.695 / 06$ \\
\hline Indústria automotiva e de fertilizantes & Lei $1.349 / 02$ \\
\hline Indústria de confecção & Lei $2.229 / 09$ \\
\hline Lixobom & Lei $1.095 / 99 ;$ Dec. $2.912 / 06$ \\
\hline Proindústria & Lei $1.385 / 03 ;$ Dec. $2.845 / 06$ \\
\hline Prologística & Lei $2.679 / 12$ \\
\hline Prosperar & Lei $1.355 / 02 ;$ Dec. $1.768 / 03 ;$ Lei 1.746/06 \\
\hline Redução da base de cálculo & Lei $1.303 / 02$ \\
\hline Suspensão de alíquota & Lei $1.375 / 03$ \\
\hline Vendas pela Internet (E-commerce) & Lei 1.641/05 \\
\hline
\end{tabular}

Fonte: Elaborado pelos autores com dados da pesquisa de campo, 2014.

Em linhas gerais, os pontos comuns de que tratam esses incentivos, são:

1. Redução na base de cálculo do ICMS de até $75 \%$, dependendo do tipo de operação comercial e produto;

2. Crédito fiscal presumido em operações realizadas por contribuinte cadastrado e estabelecido no Tocantins;

3. Suspensão de alíquota de ICMS para veículos automotivos, óleo diesel e querosene de aviação;

4. Isenção do ICMS, em casos específicos, como o de produtos em estado natural produzidos por produtor rural no Estado, a exemplo o peixe de água doce, entre outros produtos primários;

5. Formalização por parte do beneficiário de Contrato com a SIC e Termo de Acordo de Regimes Especiais - TARE com a SIC e SEFAZ-TO;

6. Obrigatoriedade do recolhimento de $0,3 \%$ sobre o valor do faturamento mensal incidente no benefício concedido para $\mathrm{O} F \mathrm{FE}$, a título de contribuição para custeio. 
A depender do tipo de benefício fiscal concedido, algumas outras especificidades são acrescidas, no entanto, essas são regras estabelecidas de forma geral quando da concessão desses incentivos no Estado do Tocantins.

Esses 12 programas beneficiaram um total de 943 empresas, entre $1999 \mathrm{e}$ 2012, sendo que 724 ainda estavam ativas até janeiro de 2014. Desse total geral, os programas Comércio Atacadista e Proindústria foram os que tiveram mais concessões, sendo 466 e 277, respectivamente. Em termos percentuais, esses dois programas respondem conjuntamente por aproximadamente $80 \%$ de todos os incentivos fiscais concedidos no período em questão. No entanto, do total dessas 743 concessões, aproximadamente $48 \%$ se encontram suspensas ou revogadas, isto significa que pouco mais de $52 \%$ desses benefícios estão ativos atualmente (ARAÚJO, 2014).

\section{ANÁLISE DA PERCEPÇÃO DOS ATORES INSTITUCIONAIS SOBRE A POLÍTICA DE CONCESSÃO DE INCENTIVOS FISCAIS NO ESTADO DO TOCANTINS}

i. Identificação da eficácia das atuais estratégias de governo para a atração de empreendimentos

Com relação à estratégia estadual de promoção comercial do Estado, constatou-se que, na opinião da maioria dos entrevistados, essa tática de atração de empreendimentos não tem apresentado eficácia, conforme pode ser observado na Tabela 1.

Tabela 1. Identificação das estratégias de governo que atualmente é mais eficaz para a atração de empresas para o Tocantins na opinião dos entrevistados

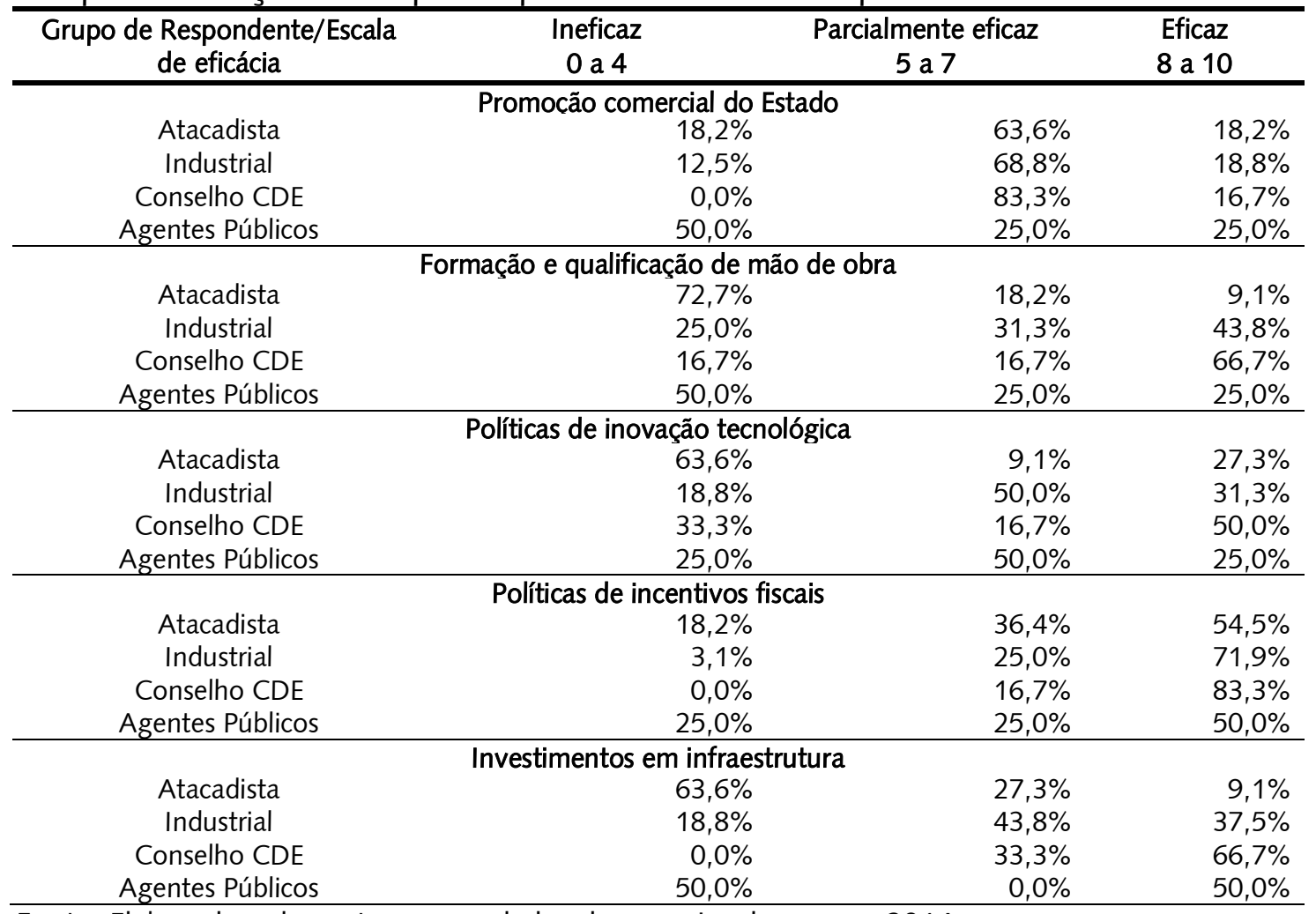

Fonte: Elaborado pelos autores com dados da pesquisa de campo, 2014. 
No caso dos empresários dos setores atacadistas e industriais, o percentual de entrevistados que consideraram essa estratégia de governo como eficaz na atração de investimentos ficou em pouco mais de 18\%. Entre os conselheiros do CDE, esse percentual foi de $16,7 \%$ e $25 \%$ entre os agentes públicos (Tabela 1 ).

Essa percepção de ineficácia pode ser vista na fala dos entrevistados. Um dos empresários do ramo atacadista chama a atenção para o fato de que, a promoção do Estado por parte do governo tem sido mais para fora do Tocantins, e alerta: "mas, eu vejo, que não há uma preparação pro empresariado do Tocantins explorar esse mercado daqui, porque seria uma riqueza maior. [...]" (EA48).

Por parte do setor da indústria, também se observou a mesma percepção. Indo além disso, outro empresário salienta que mais que atrair empresas, o Estado deveria pensar em "gerar" empresas e esclarece isto dizendo:

eu defendo a ideia que o Tocantins, os governos, as entidades patronais, tinha que parar de pensar em atrair, para pensar em gerar. Quando eu falo em atrair, eu to falando de trazer empreendedores que transformem o tocantinense em empregado, eu to falando em gerar emprego. Por que não começar a pensar em gerar empresas, gerar empresários. Por que se você gera empresário e empresas, automaticamente você tá gerando empregos (EI28).

Com relação à opinião dos respondentes sobre a eficácia da estratégia de formação e qualificação de mão de obra, nota-se uma dicotomia no resultado dos percentuais verificados para este item entre os atacadistas e os industriais. Enquanto que, para os primeiros, a eficácia dessa estratégia é de 9,1\%, para os demais esse valor aproxima-se de $44 \%$. Sobre esta estratégia, percebeu-se nitidamente a insatisfação do setor atacadista, como se observa na fala do empresário EA17 para o qual a "formação e qualificação de mão de obra são fracas, tem muita dificuldade de mão de obra".

Outros empresários desse setor, além de enfatizarem a deficiência do governo estadual na formação e qualificação da mão de obra tocantinense, ainda demonstram uma preocupação com a falta de uma política de Estado direcionada para esta área. Nessa questão, a grande maioria cita a relevância da participação de instituições educacionais (Universidade Federal do Tocantins - UFT e Instituto Federal do Tocantins - IFTO) e entidades de classe, como o Serviço Brasileiro de Apoio às Micro e Pequenas Empresas - SEBRAE, Serviço Social do Comércio - SESC, e Serviço Nacional de Aprendizagem Industrial - SENAI, e na ausência destas, eles mesmos treinam e qualificam seus funcionários.

Quanto aos empresários do segmento da indústria, percebeu-se que a grande maioria simplesmente atribuiu um valor à escala, não respondendo ao motivo de sua escolha. Isso explicaria, em parte, a dicotomia percebida entre as gradações destes e dos atacadistas. Outros entrevistados desse setor, apesar de gradarem essa estratégia como eficaz e tratarem essa questão como de grande importância, apontaram que como política de governo, a mesma não está sendo positiva, ou é feita por entidades de classe e instituição de ensino, a exemplo do que foi dito anteriormente pelo setor atacadista. Por exemplo:

esta formação e qualificação, ela não está acontecendo realmente através do estado, existe outras empresas que estão trabalhando muito em cima disso, SEBRAE, o SEST/SENAT, o SENAC, inclusive nossa 
empresa é beneficiada com isso. Não que o governo ofereça alguma coisa nesse sentido. (El14).

No que se refere à estratégia governamental de políticas de inovação tecnológica, apenas os conselheiros (Grupo 1) a consideram eficaz. Nota-se que, para os demais, essa política não tem apresentado eficácia na atração de empresas e investimentos para o Estado. Para a maioria do empresariado industrial, a política estadual de inovação tecnológica também não tem sido eficaz, sendo que apenas $31,3 \%$ demonstraram-se satisfeitos com esta estratégia de governo. No que se refere a essa questão, alguns afirmam que "a maioria das próprias empresas elas mesmas tem seu trabalho seu desenvolvimento" (EIO3), e "normalmente, a empresa quando vem se instalar aqui, ela já tem uma técnica especifica. Eu não vejo algo mais, por parte do Estado, que esteja contribuindo" (EI36).

A política de incentivo fiscal foi a única em que a maioria dos entrevistados de todos os grupos concordou como sendo a estratégia mais eficaz para atração de empresas no Tocantins. Para alguns dos respondentes do setor atacadistas, ela é "ótima", "muito boa", e muito importante para atrair empresas para o Estado, como afirma o empresário EA23 "é nos incentivos fiscais como estratégia de governo pra trazer investimento pro Estado. [...] O Tocantins é um estado sem indústria, então automaticamente, pra trazer empresários, tem que dar incentivo fiscal pra que ele se estabeleça no Tocantins".

Para a maioria dos empresários do setor industrial, esses incentivos fiscais são "muito importantes" para diminuir os custos, e para a competitividade das empresas do Estado em relação aos outros estados. Entre a maioria dos conselheiros e agentes públicos, essa percepção positiva se confirma, sendo também considerada como uma política dinâmica onde a carga tributária é uma das menores do país.

A última estratégia avaliada como tática de governo para atração de empresas para o Estado foi a de investimento em infraestrutura. Para a grande maioria dos empresários do setor atacadista, essa tática não tem sido producente, sendo que apenas 9,1\% consideram-na eficaz. De acordo com a análise das entrevistas dos mesmos, essa política "deixa a desejar" em nível de Estado, como, por exemplo, pode ser percebido na fala de alguns empresários desse segmento na região Norte do Tocantins. Na opinião do empresário EA04 "não precisa nem falar, de tanto que tá ruim, principalmente aqui pra região norte. As estradas estão péssimas. Outra coisa que tá uma vergonha, é atravessar o rio Araguaia, daqui pro Pará em uma balsa [...] demora e é muito caro. [...]".

Para os industriais, essa falta de infraestrutura no Estado não é só na malha viária, mas também na questão da energia, telecomunicação, ferrovia, aeroportos, e outros. Nesse quesito, os conselheiros, em sua maioria, consideram como uma estratégia eficaz, mas chamam a atenção para a manutenção das rodovias, como afirma o conselheiro C08, "investimento em infraestrutura, isso é uma tônica aqui, nós temos aí quase $10.000 \mathrm{~km}$ de rodovias. Agora tem que ter manutenção, não adianta fazer e deixar abandonada". 
ii. Identificação dos motivos mais relevantes para implantação ou ampliação de empreendimentos no Estado do Tocantins

A identificação dos motivos considerados pelos agentes institucionais como os mais relevantes para a implantação ou ampliação de um empreendimento no Estado foi realizada apenas com o setor econômico dos empresários dos segmentos da indústria e do comércio atacadista.

Aqui se confirmou o que a maioria dos respondentes apontou no item anterior, ou seja, o incentivo fiscal, além de ser a estratégia de governo considerada atualmente como a mais eficaz para a atração de empresas, também é tido como o principal motivo para os empresários tocantinenses implantarem ou ampliarem seus empreendimentos no Estado.

Gráfico 1. Motivos mais relevantes para implantar ou ampliar um empreendimento no Estado do Tocantins de acordo com os atores institucionais.

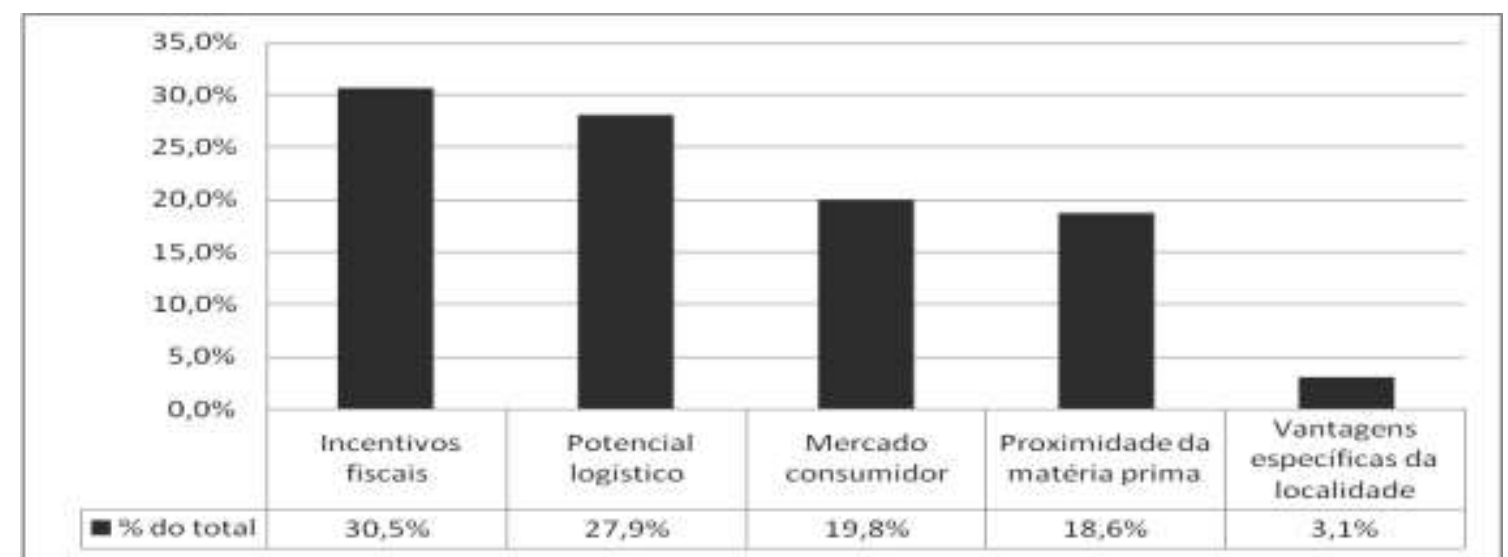

Fonte: Elaborado pelos autores com dados da pesquisa de campo, 2014.

Observa-se que, dentre os motivos indicados no Gráfico 1, o incentivo fiscal teve mais de $30 \%$ das indicações dos empresários. O potencial logístico, o mercado consumidor, a proximidade da matéria-prima e as vantagens específicas da localidade ficaram, respectivamente em $2^{\circ}, 3^{\circ}, 4^{\circ}$ e $5^{\circ}$ lugar pela ordem de relevância.

Chama-se a atenção para o item das vantagens específicas da localidade, no que se refere ao entendimento dos entrevistados sobre essas vantagens. Estas se referem, entre outras coisas: ao fato de a cidade ter uma melhor estrutura para se viver e negociar; ser um polo universitário; a empresa ser natural da localidade, e assim conhecer melhor os seus clientes e o mercado local e, ainda, ter conhecimento sobre a mão de obra local e a gestão municipal. Percebe-se, nessas indicações de vantagens específicas da localidade, algo que vai ao encontro das "externalidades jacobianas", ou seja, externalidades urbanas, isto é, os ganhos aglomerativos locais internos em um centro urbano (LEMOS, Santos e Crocco, 2003). 
iii. Percepção dos respondentes sobre as políticas de incentivos fiscais do Estado do Tocantins

Entendendo que quanto mais institucionalizada for uma regra, menor o grau de questionamento ela terá, apresenta-se, aqui, os resultados da pesquisa quanto à identificação do grau de institucionalização da política de incentivos fiscais do Tocantins, na percepção que os atores institucionais têm sobre os incentivos fiscais do Estado do Tocantins. Nesse caso, a Tabela 2 demonstra o grau de satisfação que os empresários entrevistados têm dessa política.

Tabela 2. Avaliação da política de incentivo fiscal do Tocantins por parte dos empresários

\begin{tabular}{|c|c|c|c|}
\hline $\begin{array}{c}\text { Setor Respondente/Escala de } \\
\text { satisfação }\end{array}$ & $\begin{array}{c}\text { Insatisfeito } \\
0 \text { a } 4 \\
\end{array}$ & $\begin{array}{c}\text { Parcialmente satisfeito } \\
5 \text { a } 7 \\
\end{array}$ & $\begin{array}{l}\text { Satisfeito } \\
8 \text { a } 10\end{array}$ \\
\hline \multicolumn{4}{|c|}{ Confiabilidade } \\
\hline Atacadista & $41,7 \%$ & $25,0 \%$ & $33,3 \%$ \\
\hline Industrial & $3,1 \%$ & $50,0 \%$ & $46,9 \%$ \\
\hline \multicolumn{4}{|c|}{ Clareza } \\
\hline Atacadista & $41,7 \%$ & $33,3 \%$ & $25,0 \%$ \\
\hline Industrial & $12,5 \%$ & $31,3 \%$ & $56,3 \%$ \\
\hline \multicolumn{4}{|c|}{ Acessibilidade } \\
\hline Atacadista & $41,7 \%$ & $33,3 \%$ & $25,0 \%$ \\
\hline Industrial & $9,7 \%$ & $61,3 \%$ & $32,3 \%$ \\
\hline \multicolumn{4}{|c|}{ Prazos } \\
\hline Atacadista & $25,0 \%$ & $8,3 \%$ & $66,7 \%$ \\
\hline Industrial & $12,9 \%$ & $54,8 \%$ & $32,3 \%$ \\
\hline
\end{tabular}

Fonte: Elaborado pelos autores com dados da pesquisa de campo, 2014.

Em termos gerais, a Tabela 2 demonstra que a maioria dos empresários do ramo atacadista está insatisfeita com a confiabilidade, a clareza e a acessibilidade da política de incentivos fiscais. Somente com relação aos prazos é que indicaram estar satisfeitos. Já entre os do setor da indústria, percebeu-se que estes, em sua maioria, estão parcialmente satisfeitos em relação à confiança e acessibilidade dessa política, e satisfeitos com sua clareza e com seus prazos.

No que se refere à questão da confiabilidade da política de incentivo fiscal tocantinense, notou-se que pouco mais de $33 \%$ do atacadista a consideram confiável. Entre os industriais, esse percentual de confiabilidade se aproximou de $47 \%$, contudo, na análise de suas falas, observou-se o contrário. Percebeu-se, inclusive, um sentimento de insegurança, atribuído por alguns dos respondentes à grande quantidade de mudanças ocorridas nas bases legais, ou seja, nas instituições dos benefícios. Para a maioria dos atacadistas e industriais, o excesso de mudanças nas leis e a falta de uma lei definitiva são motivos para não confiarem nessa política. Como se observa nas seguintes falas:

não é muito confiável. Como não existe uma política definida, e quando não existe um grau de confiabilidade nesse sentido, isso deixa as pessoas inseguras, nesse caso o comerciante fica inseguro. (EA48).

No ano de 2013, o governo do estado alterou alguns incentivos causando incertezas, com isso houve uma queda na credibilidade. (EI22).

Com relação ao grau de clareza, também há uma divergência de respostas entre os entrevistados dos setores do atacado e da indústria. Percentualmente, 
apenas $25 \%$ dos atacadistas estão satisfeitos com a clareza das regras instituídas nos benefícios fiscais do Estado, em contrapartida, para 56,3\% dos empresários das indústrias elas são claras.

Da análise realizada nas entrevistas, observou-se que o discurso da maioria corrobora os dados quantitativos levantados, apontando, entre outras coisas, o excesso de mudanças institucionais e de burocracia, bem como o desconhecimento das regras do jogo.

Nesse caso, a maioria dos atacadistas está insatisfeita com a clareza dessas regras, e atribuem isto, entre outras coisas, à grande variabilidade e mudanças dessas leis, ao excesso de burocracia e à falta de divulgação dos incentivos:

não ficam claras as regras. [...] Precisa o Estado fazer uma política mais voltada pro próprio Estado. [...] deixar claro, pras pessoas como é que funciona o processo, o que você tem que fazer pra ter o benefício, deixar claro quais são seus deveres, suas obrigações. (EA48).

Já para os industriais, as regras dessa política são claras e suficientes, como destaca o empresário El51 ao dizer "mas realmente, principalmente no nosso caso que é o Termo de Acordo de Regime Espacial (TARE), ele está bem detalhado, tá bem informado".

$\mathrm{Na}$ análise da acessibilidade dos benefícios fiscais, grande parte dos atacadistas considera como inacessível ou parcialmente acessível. Em especifico, apontaram a falta de informação sobre os incentivos e a necessidade de se ter "conhecimento" político para ter um maior acesso aos benefícios.

Não é fácil, essa disponibilidade desse beneficio, falando diretamente da questão do Termo de Acordo do setor atacadista. Você tem que ter meios, conhecimento, diretamente ligado ao governo, um deputado, pra você chegar a ter acesso. Se você não tiver esses meios, você tem dificuldade de chegar a esse beneficio. Já foi mais fácil, hoje está muito reservado. [...] (EA39).

Quanto à opinião da maioria dos industriais, de maneira geral, opinaram como parcialmente acessíveis. No entanto, alguns apontaram a forte burocracia que há na concessão dos incentivos e cobraram uma atenção maior do governo para os empresários locais. Não focar só em atrair os de fora, mas manter os que estão no Estado.

Acho que tem muita burocracia, e dificuldade de ter acesso. [...] Eu acho que precisa ter mais acessibilidade, não só para o empresário que vem de fora com proposta mirabolante, mas para o empresário que tá aqui, que produz aqui, que gera emprego e que gera renda aqui na cidade. (EIO3).

Com relação à questão, se os prazos de análise e aprovação dos benefícios estão a contento dos entrevistados, em termos gerais, os dois grupos concordam que os prazos estão condizentes com o esperado.

Buscando perceber, ainda, na opinião dos empresários beneficiados, qual a relevância dos incentivos fiscais para a manutenção ou ampliação das suas empresas no Estado, constatou-se que esse benefício é importante tanto para o setor atacadista quanto para o industrial. 
Tabela 3. Identificação do grau de importância que os incentivos fiscais tiveram ou têm para os empresários na atração e manutenção de sua empresa no Estado do Tocantins

\begin{tabular}{ccrr}
\hline $\begin{array}{c}\text { Setor Respondente/Escala de } \\
\text { importância }\end{array}$ & $\begin{array}{c}\text { Pouco } \\
\text { importante } \\
0 \text { a } 4\end{array}$ & $\begin{array}{c}\text { Parcialmente } \\
\text { importante } \\
5 \text { a } 7\end{array}$ & $\begin{array}{c}\text { Importante } \\
8 \text { a } 10\end{array}$ \\
\hline Comércio Atacadista & $0,0 \%$ & $25,0 \%$ & $75,0 \%$ \\
Indústria & $0,0 \%$ & $16,1 \%$ & $83,9 \%$ \\
\hline
\end{tabular}

Fonte: Elaborado pelos autores com dados da pesquisa de campo, 2014.

Nota-se que esse é o único item em que não houve uma pontuação negativa, ou seja, não há dúvidas quanto à relevância que esses incentivos têm para as empresas no Estado. Essa importância é percebida, por exemplo, na fala do empresário EA27, que diz: "a manutenção desse incentivo é muito importante pra que a empresa se mantenha no mercado. [...] Esse beneficio faz a diferença, sem os incentivos não estaríamos aqui".

Analisando as entrevistas realizadas com os industriais, observou-se que estes também declararam a importância dos incentivos fiscais para a permanência dos mesmos no Estado. Neste caso, destacam sua relevância para a diminuição dos custos, terem poder de barganha, ser mais competitivos, ter crescimento, e ainda gerar mais empregos, entre outras vantagens.

Ainda com relação à avaliação da política de incentivo fiscal tocantinense, buscou-se também identificar quais os resultados que os entrevistados têm percebido nos diversos setores econômicos do Estado, que eles poderiam atribuir a essa política estadual. Como resultado da gradação atribuída pelos entrevistados, tem-se a Tabela 04.

Tabela 04. Percepção, por parte dos respondentes, dos resultados advindos dos incentivos fiscais concedidos para os diversos setores econômicos do Tocantins

\begin{tabular}{|c|c|c|c|}
\hline \multirow{2}{*}{ Grupo de Respondente/Escala de resultado } & Baixo & Médio & Alto \\
\hline & 0 a 4 & \multicolumn{2}{|c|}{$\frac{0 \text { a } 4}{\text { Aumento da produtividade }}$} \\
\hline Atacadista & $\begin{array}{r}\text { rodutividade } \\
8,3 \%\end{array}$ & $50,0 \%$ & $41,7 \%$ \\
\hline Industrial & $0,0 \%$ & $28,1 \%$ & $71,9 \%$ \\
\hline Conselho CDE & $33,3 \%$ & $0,0 \%$ & $66,7 \%$ \\
\hline Agentes Públicos & $0,0 \%$ & $66,7 \%$ & $33,3 \%$ \\
\hline \multicolumn{4}{|c|}{ Aumento da geração de emprego local } \\
\hline Atacadista & $8,3 \%$ & $33,3 \%$ & $58,3 \%$ \\
\hline Industrial & $0,0 \%$ & $12,9 \%$ & $87,1 \%$ \\
\hline Conselho CDE & $16,7 \%$ & $33,3 \%$ & $50,0 \%$ \\
\hline Agentes Públicos & $0,0 \%$ & $0,0 \%$ & $100,0 \%$ \\
\hline \multicolumn{4}{|c|}{ Aumento da renda local } \\
\hline Atacadista & $16,7 \%$ & $41,7 \%$ & $41,7 \%$ \\
\hline Industrial & $0,0 \%$ & $19,4 \%$ & $80,6 \%$ \\
\hline Conselho CDE & $2,0 \%$ & $33,3 \%$ & $50,0 \%$ \\
\hline Agentes Públicos & $0,0 \%$ & $0,0 \%$ & $100,0 \%$ \\
\hline \multicolumn{4}{|c|}{$\mathrm{Na}$ descentralização das atividades econômicas } \\
\hline Atacadista & $18,2 \%$ & $45,5 \%$ & $36,4 \%$ \\
\hline Industrial & $6,5 \%$ & $41,9 \%$ & $51,6 \%$ \\
\hline Conselho CDE & $16,7 \%$ & $16,7 \%$ & $66,7 \%$ \\
\hline Agentes Públicos & $0,0 \%$ & $66,7 \%$ & $33,3 \%$ \\
\hline
\end{tabular}

Fonte: Elaborado pelos autores com dados da pesquisa de campo, 2014. 
Numa visão geral dos resultados apurados nessa questão, percebeu-se que a grande maioria dos entrevistados considera "alto" o grau de relação existente entre os incentivos fiscais concedidos pelo Estado e o aumento da produtividade, a geração emprego, a renda e a descentralização das atividades econômicas do Tocantins.

Analisando as falas dos respondentes, constata-se uma confirmação dos resultados quantitativos na medida em que, para a maioria dos empresários da indústria que tem incentivos fiscais, aumenta a produtividade $\mathrm{e}$, consequentemente, o número de empregos gerados e a renda no local em que existam empresas beneficiadas. Destacam-se, nesse sentido, as seguintes observações dos entrevistados:

\begin{abstract}
porque devido aos impostos, ter um desconto, com esse desconto eles podem gerar mais emprego e gerar mais circulação de produtos. (EI40). Se paga-se menos impostos, com certeza aumenta-se a produção e geram-se mais empregos, pois se necessita de mais trabalhadores. (EI35).
\end{abstract}

Para os entrevistados do comércio por atacado, é nítido o aumento na geração de emprego, no entanto, alguns salientaram que isto não tem se refletido no aumento dos salários. Sobre essa questão, o empresário atacadista EA31 afirma que, mesmo com o aumento do número de empregos gerados, não tem percebido aumento da renda local. Essa percepção também é percebida na seguinte fala:

aumento da renda local também não acredito, porque a maioria dos Termos de Acordos que saíram, as empresas é de fora, e não gera renda local quase nada. (EA33).

Com relação ao item de descentralização das atividades econômicas, ao fazer a análise das entrevistas, percebeu-se que a maioria dos entrevistados entende esta descentralização como uma diversificação das atividades econômicas internas ao estado ou região em que estão instalados. No entanto, a questão da descentralização das atividades econômicas como sendo aquela que sai do eixo da BR-153, indo mais para o interior do Estado, também foi apontada.

\title{
5 CONSIDERAÇÕES FINAIS
}

A questão centralizadora e norteadora desta pesquisa foi a análise das percepções que os atores institucionais têm da política de benefícios fiscais tocantinense, sob a ótica do NE.

Assim, identificou-se, em primeiro lugar, o marco legal dos programas de concessão dos benefícios fiscais tocantinenses, especialmente do Comercio Atacadista e do Proindústria. Nesse caso, identificou-se que os dois programas em específico tiveram diversas mudanças na instituição de suas regras, ou seja, em seu arcabouço legal. Constatou-se que, na opinião dos atores institucionais, a grande quantidade de alterações efetuadas na base legal dos programas de benefícios fiscais do Estado do Tocantins reflete negativamente na avaliação que estes fazem dessa política de governo. 
Em segundo lugar, percebeu-se que os incentivos fiscais concedidos pelo Estado foram considerados, pelos atores institucionais entrevistados, como sendo atualmente a estratégia de governo mais eficaz para atrair empresas. Além disso, esses incentivos também foram apontados como o principal motivo para os empresários implantarem ou ampliarem seus empreendimentos no Estado.

Em terceiro lugar, quanto às percepções que os atores institucionais têm da política de concessão de incentivos fiscais do Estado, inicialmente, verificou-se que a avaliação que estes fazem da confiabilidade, clareza, acessibilidade e prazos desta política é díspar entre os atacadistas e os industriais. Para os primeiros, a clareza e a acessibilidade não são satisfatórias, apenas quanto aos prazos é que demonstram estar satisfeitos. Já os segundos consideram-se parcialmente satisfeitos em relação à confiança e acessibilidade, e satisfeitos com sua clareza e com seus prazos.

Sobre a percepção dos respondentes em relação aos resultados percebidos como advindos dos incentivos fiscais, na dinâmica econômica do Estado, constatou-se que a maioria dos respondentes dos três grupos entrevistados concorda que o grau de relação existente entre o aumento da geração de emprego e o da renda local é alto. Para eles, se mais empresas receberem benefícios fiscais, mais elas se tornarão competitivas, mais vão produzir, gerando, assim, mais emprego nos locais em que estão instaladas e, consequentemente, aumenta a renda local.

Sobre a iminência de mudanças institucionais com o término ou mesmo limitação nas políticas estaduais de concessão de benefícios fiscais, identificou-se cinco grandes eixos de possíveis estratégias que, adotadas, poderiam garantir o poder de atração de empreendimentos, quais sejam: a infraestrutura ou potencial logístico (investimento e melhoria nessas áreas); a industrialização (buscar trazer indústrias para o Estado, de preferência aproveitando a matéria-prima local); a qualificação de mão de obra (investimento na qualificação e profissionalização mão de obra local); a tecnologia (investimento em empresas de base tecnológica ou parques tecnológicos); e a divulgação do Estado (melhor divulgação do Estado e suas potencialidades).

Percebeu-se, com isso, ser necessário que, tanto os gestores públicos estaduais quanto os municipais de nosso Estado, busquem observar o que os setores econômicos têm a dizer sobre o assunto para, em alguma medida, buscarem soluções conjuntas para essa questão.

Por fim, respondendo ao problema que suscitou nesta pesquisa, percebeuse que, para a maioria dos empresários entrevistados, essa política é muito importante para a implantação, manutenção e ampliação de suas empresas no Estado. No entanto, o grau de confiabilidade que estes têm nessa política é insatisfatório. Além do excesso de alterações na base legal, ou seja, nas instituições formais dos incentivos, essas mudanças ocorrem de forma abrupta e sem aviso, o que deixa os comerciantes inseguros quanto a sua confiabilidade. A solução apontada seriam políticas de governo de longo prazo e definitivas, que reduziria mais as incertezas, dando uma maior confiança e segurança sobre as "regras do jogo" envolvidas nessa política, promovendo, assim, a institucionalização da mesma. Isso vai ao encontro dos apontamentos do $\mathrm{NE}$, no que se refere ao papel das instituições na redução das incertezas e no estabelecimento de estruturas estáveis para as interações humanas. 


\section{REFERÊNCIAS}

AYALA ESPINO, José. Instituciones y economía: una introducción al neoinstitucionalismo económico. México: FCE, 1999.

Instituciones para mejorar el desarrollo. Un nuevo pacto social para el crecimiento y el bienestar. México: FCE, 2003.

ARAÚJO, Maria R. N. Análise institucional da concessão de benefícios fiscais como política de desenvo/vimento do estado do Tocantins de 1999 a 2012. Dissertação (Mestrado em Desenvolvimento Regional) - Programa de Pós-Graduação em Desenvolvimento Regional da Universidade Federal do Tocantins, Palmas, 2014.

BARDIN, Laurence. Análise de Conteúdo. 5. ed. Lisboa: Edições 70, 2009.

COASE, R., La naturaliza económica de la empresa, FCE, México, 1993.

COLOGNESE, Silvio A.; MELO, José L. B. A técnica de entrevista na pesquisa social. Cadernos de Sociologia, Porto Alegre, v. 9, p. 143-159, 1999.

CONCEIÇÃO, Octavio Augusto Camargo. Instituições, crescimento e mudança na ótica institucionalista. Porto Alegre: Fundação de Economia e Estatística Siegfried Emanuel Heuser, 2001. Disponível em:

<http://cdn.fee.tche.br/teses/teses_fee_01.pdf>. Acesso em 20 jun. 2013.

GIBBS, Graham. Análise de dados qualitativos. Porto Alegre: Artmed, 2009.

GIL, Antônio C. Métodos e técnicas de pesquisa social - 6. ed. - São Paulo: Atlas, 2009.

LEMOS, Mauro B.; SANTOS, Fabiana; CROCCO, Marco. Arranjos Produtivos Locais industriais sob ambientes periféricos: os condicionantes territoriais das externalidades restringidas e negativas. In: ENCONTRO NACIONAL DE ECONOMIA, XXXI, 2003, Porto Seguro. Disponível em: < http://www.anpec.org.br/encontro2003/artigos/E31.pdf>. Acesso em: 03 maio 2014.

MARTINS, Gilberto de A.; THEÓPHILO, Carlos R. Metodologia da investigação científica para ciências sociais aplicadas. 2.ed. São Paulo: Atlas, 2009.

NORTH, Douglas C. Custos de transação, instituições e desempenho econômico. Trad. Elizabete Hart. Rio de Janeiro: Instituto Liberal, 1998.

Instituciones, cambio institucional y desempeño económico. México:

$\overline{\text { Fondo }}$ de cultura económica, 2001.

PEDROZA JUNIOR, Dinilson; et al. Instituições e políticas regionais: uma proposta para uma nova SUDENE. Rev. Economia e Política. São Paulo, v 31, n. 5, de 
2011. Disponível em:

$<$ http://www.scielo.br/scielo.php?script=sci_arttext\&pid =S0101-

31572011000500007\& Ing=en\&nrm=iso >. Acesso em: 06 fev. 2013.

TOCANTINS (Estado). Secretaria da Fazenda. Relatório de Termos de Acordo (TARE), Convênios e Protocolos. SEFAZ-TO, 2014. Mimeo.

. Secretaria da Indústria e Comércio. SIC-TO, 2013. Disponível em:

<http://sic.to.gov.br>. Acesso em: 20 jan. 2013.

Lei $\mathrm{n}^{0}$ 1.201, de 29 de dezembro de 2000. Concede crédito fiscal

presumido do ICMS nas operações que especifica, e adota outras providências.

Disponível em:

<http://www.al.to.gov.br/arq/AL_arquivo/23757_Lei1201_00.pdf>. Acesso em: 02 fev. 2013. (Tocantins, 2013a)

. Lei no 1.385, de 9 de julho de 2003. Institui o Programa de Industrialização Direcionada - PROINDUSTRIA, e adota outras providências. Disponível em: <http://dtri.sefaz.to.gov.br/legislacao/ntributaria/Leis/lei1.38503.htm >. Acesso em: 02 fev. 2013. (Tocantins, 2013b).

WILLIAMSON, O. E., Las instituciones económicas del capitalismo: empresas, mercados y contratos relacionales, FCE, México, 1993.

WILLIAMSON, O. E., The New Institutions Economics: tacking stocks, looking ahead. Journal of Economic Literature, v. XXXVIII, p. 595-613, Sept. 2000.

Submetido em 12/03/2015

Aprovado em 26/12/2015

\section{Sobre os autores}

Waldecy Rodrigues

Professor do Programa de Mestrado em Desenvolvimento Regional da Universidade Federal do Tocantins.

Endereço para correspondência: Av. NS 15 (Saida para Paraíso) Alameda C No 14 Bloco II. Centro. 77020210 - Palmas - TO - Brasil.

E-mail: rosicleidearaujo@hotmail.com

\section{Maria Rosicleide do Nascimento Araújo}

Economista, Mestre em Desenvolvimento Regional. Economista na Secretaria da Fazenda do Estado do Tocantins.

Endereço para correspondência: Esplanada das Secretarias, Centro. 77000-000 - Palmas - TO Brasil.

E-mail: waldecy@terra.com.br 